\title{
First insight of exogenous addition of proline and glycinebetaine to mitigate fluorine toxicity effects on common bean seedlings
}

\author{
Sara Chahine, ${ }^{1}$ Vittoria Giannini, ${ }^{1}$ Pier Paolo Roggero, ${ }^{1,2}$ Sara Melito ${ }^{1}$ \\ ${ }^{1}$ Department of Agricultural Sciences; ${ }^{2}$ Desertification Research Centre, University of Sassari, Italy
}

Highlights

- Exogenous glycinebetaine and proline were able to counteract F inhibitory effects on Phaseolus vulgaris seedlings growth.

- Sodium fluoride (NaF) showed more toxic effect than potassium fluoride (KF) on Phaseolus vulgaris seedlings growth.

- Proline was more effective than glycinebetaine in alleviating $F$ toxicity effects on seedlings growth.

\begin{abstract}
To counteract fluoride $(\mathrm{F})$ stress-induced adverse effects on plants, one approach is the application of exogenous potential osmoprotectants such as proline (Pro) and glycinebetaine (GB). This experiment was carried out to evaluate the effects of exogenous application of Pro and GB on germination and growth of common bean seeds after potassium fluoride (KF) and sodium fluoride $(\mathrm{NaF})$ exposure. The study was replicated under two different temperatures: the normal temperature required for seeds growth $\left(20^{\circ} \mathrm{C}\right)$ and a higher $\left(25^{\circ} \mathrm{C}\right)$ favourable for bean cultivation in Africa, the region most polluted with $\mathrm{F}$. The results indicated that the beneficial effects of external supply of Pro and GB varied depending on temperature and the source of salt stress. NaF
\end{abstract}

Correspondence: Vittoria Giannini, Department of Agricultural Sciences, University of Sassari, Sassari 07100, Italy.

E-mail: vgiannini@uniss.it

Key words: Fluoride; salt stress; salt tolerance; osmoprotection; osmolytes.

Acknowledgements: the authors wish to thank Mario Antonello De Roma and Domenico Carta for the technical support. This study was conducted in the context of the Agreement between the Department of Agricultural Science of the University of Sassari and the Faculty of Agricultural Sciences and Veterinary Medicine of the Lebanese University and was funded by EU H2020 FLOWERED project 690378 'de - FLuoridation technologies for imprOving quality of WatEr and agRo - animal products along the East African Rift Valley in the context of aDaptation to climate change'.

Received for publication: 14 October 2020.

Revision received: 9 December 2020.

Accepted for publication: 10 December 2020.

(C) Copyright: the Author(s), 2021

Licensee PAGEPress, Italy

Italian Journal of Agronomy 2021; 16:1754

doi:10.4081/ija.2020.1754

This article is distributed under the terms of the Creative Commons Attribution Noncommercial License (by-nc 4.0) which permits any noncommercial use, distribution, and reproduction in any medium, provided the original author(s) and source are credited. showed a more toxic effect than KF on growth of Phaseolus vulgaris seeds. Overall, Pro was more effective than GB to alleviate the undesirable effect of salt stress on morphological attributes under NaF stress (improving by 50\% and 39\% the length and the number of lateral roots), and especially at higher temperature the recovery role of Pro and GB was more relevant reaching the same value found under control conditions for the length of hypocotyl $(3.28 \mathrm{~cm})$.

\section{Introduction}

Soil and ground water contamination with fluoride $(F)$ is a serious problem in many countries with severe implications for human health. World Health Organization (WHO) established the safe limit of $1.5 \mathrm{mg} \mathrm{L}^{-1}$ in drinking water (Banerjee and Roychoudhry, 2019a). However, in several countries (America, Asia, Middle East and Africa), the F content in drinking water largely exceeds the permissible value. Furthermore, there is not a threshold limit value for F content in soil and plants.

In plants, the endogenous $\mathrm{F}$ level approximately increases of 3 ppm every $100 \mathrm{ppm}$ in soil, up to about $2000 \mathrm{ppm}$ level as reported by Bharti et al (2017). F gradually accumulates in plant tissues with time and when it reaches high level induces physiological and growth disorders, such as inhibition of germination and reduction of plant growth and biomass accumulation (Yadu et al., 2016).

From a physiological point of view, the most frequent effects associated to $\mathrm{F}$ toxicity are photosynthesis alteration, nitrogen assimilation decrease, presence of chlorosis, chlorophyll disruption, alteration of enzyme activities (ribulose 1,5-biphosphate carboxylase; protein synthesis) (Panda, 2015). These symptoms converge in a general oxidative stress condition with an overproduction of reactive oxygen species (ROS) (Debska et al., 2012).

Besides, $\mathrm{F}$ toxicity is related to its permeability in plant tissues. $\mathrm{F}$ is absorbed by roots chloride channels and translocated in the whole plant through the xylematic flow (Banerjee and Roychoudhury, 2019a, 2019b). Once reached the plant cell, F might reduce the plasm membrane $\mathrm{H}+$ /ATPase activity causing the activation of abiotic signals cascade.

Plant stress symptoms associated with F toxicity are shown gradually and tend to be more severe under protracted exposure (Hong et al., 2016).

Soil and water are the principal source of $F$ that is then accumulated in plant tissues and in edible parts, determining a potential risk for the entire food chains (Mondal and Gupta, 2015). 
Among the different responses of plant to salts stresses, the most common is the overproduction of different type of compatible solutes (proline, glycine betaine, sorbitol, mannitol, etc.) (Ashraf and Foolard, 2007). The accumulation of osmolytes acts as membrane stabilizer and represents a temporary source of carbon and nitrogen that finally detoxicates plant cell from free radicals (Chandrakar et al., 2016).

Indeed, F toxicity in plant could be potentially mitigated screening candidate compounds, acting as osmolytes, that can be provided exogenously. Several studies revealed a key role of proline (Pro) and glycinebetaine (GB) in enhancing plants' tolerance to $\mathrm{NaCl}$ stress. In particular, the exogenous application of Pro in rice and lupin (Nounjan et al., 2012; Rady et al., 2015) revealed a reduction of stress symptoms in treated plants. Similar observations have been reported on the role of exogenous GB in enhancing the abiotic stress tolerance in different crops as well as Phaseolus vulgaris L. (Annunziata et al., 2019; Sofy et al., 2020).

Despite the promising role of these two osmolytes in mitigating the salts stress in plants, few information is available on their potential role in mitigating F stress. It has been shown that GB has a role in fluoride toxicity recovery in Cajanus cajan L. (Yadu et al., 2017), but no evidences are available for proline.

Common bean (Phaseolus vulgaris L.) is a grain legume extensively grown and consumed all over the world and represents one of the main food sources and sources of income of smallholder's farmers in Africa and Latin America (Beepe et al., 2012; Binagwa et al., 2018). These areas are already listed by the WHO as countries suffering an endemic fluorosis. The most important bean production area in eastern and southern Africa have a mean temperature $\left(15-23^{\circ} \mathrm{C}\right)$ favourable for bean growth (Wortmann et al., 1998). Beans in the Eastern Kenya, central America, central Brazil and south Africa are produced at relatively high temperature (Wortmann et al., 1998; Beebe et al., 2012).

Considering the abiotic stress mitigation properties of GB and Pro, current study was aimed to evaluate their recovery efficacy on germination response and biometric traits of bean seedling under two salts treatments $(\mathrm{NaF}$ and $\mathrm{KF})$ and two different temperature conditions $\left(20^{\circ} \mathrm{C}, 25^{\circ} \mathrm{C}\right)$.

\section{Materials and methods}

\section{Plant material and treatments}

Seeds of Phaseolus vulgaris L., Borlotto nano "BOR", were placed in petri dishes under constant temperature conditions: at $25^{\circ} \mathrm{C}$ (Experiment 1$)$ and at $20^{\circ} \mathrm{C}$ (Experiment 2).

For both experiments, seeds were treated as follow: i) Control (F0) and no osmolytes (C): $0 \mathrm{ppm}$ salt $+0 \mu \mathrm{M}$ osmolyte; ii) Control (F0) and GB: 0 ppm salt $+75 \mu \mathrm{M} \mathrm{GB}$; iii) Control (F0) and Pro: 0 ppm salt $+10 \mathrm{mmol}$ Pro; iv) Potassium fluoride (KF) and no osmolytes (C): 200 ppm KF $+0 \mu \mathrm{M}$ osmolyte; v) KF and GB: 200 ppm KF $+75 \mu \mathrm{M}$ GB; vi) KF and Pro: $200 \mathrm{ppm} \mathrm{KF}+10 \mathrm{mmol}$ Pro; vii) Sodium fluoride (NaF) and no osmolytes (C): $200 \mathrm{ppm}$ $\mathrm{NaF}+0 \mu \mathrm{M}$ osmolyte; viii) $\mathrm{NaF}$ and GB: $200 \mathrm{ppm} \mathrm{NaF}+75 \mu \mathrm{M}$ GB; ix) NaF and Pro: 200 ppm NaF + 10 mmol Pro.

The treatment with salts was applied through soaking the seeds in solutions of deionized water (treatments $1,2,3$ ) or a solution of KF 200 ppm (treatments 4, 5, 6) or a solution of NaF 200 ppm (treatments $7,8,9$ ) for $6 \mathrm{~h}$.

The tested concentrations of osmolytes were selected after a preliminary experiment in which four different concentrations of both osmolytes were compared.

Indeed, in the preliminary investigation, various concentra- tions of $\mathrm{GB}$, i.e. $25,50,75$ and $100 \mu \mathrm{M}$ (following the procedure of Yadu et al., 2017) and Pro i.e. 3, 10, 20 and 30 mmol (based on Demil̈r and Kocaçalişkan, 2001 under $\mathrm{NaCl}$ treatment) were tested for mitigation of $\mathrm{F}$ stress on the growth of $P$. vulgaris $\mathrm{L}$. The results showed that the addition of $25,50,75$ and $100 \mu \mathrm{M}$ GB caused upsurge in lateral root length (LLR) by $161 \%, 150 \%, 188 \%$ and $154 \%$ compared to $\mathrm{F}$ stressed seedlings, respectively; while it decreased the main root length by $67 \%, 60 \%, 25 \%$ and $48 \%$, respectively. Therefore, $75 \mu \mathrm{M}$ of GB was used in this study, which showed maximum tolerance (highest increase of LR (188\%) and lowest decrease of the main root length (25\%) to F-toxicity. For Pro, the addition of 3, 10, 20 and $30 \mathrm{mmol}$ increased the LLR by $117 \%, 176 \%, 144 \%$ and $152 \%$ compared to $\mathrm{F}$ stressed seedlings; while it decreased the main root length by $60 \%, 44 \%, 47 \%$ and $46 \%$, respectively. Hence, $10 \mathrm{mmol}$ of Pro was used in this study which showed maximum tolerance $(176 \%$ of LLR and $54 \%$ of the main root length).

Out of these, the best tolerated concentration for each osmolyte was selected for the complete experiments.

According to the above-presented experimental design, the osmolytes were applied through irrigation ( $3 \mathrm{ml}$ every $30 \mathrm{~h}$ ).

\section{Germination parameters and biometric traits}

Over the 7-day-experiment, germinated seeds were recorded daily. From these records, both mean germination percentage (MG) and mean coefficient of velocity of germination (MCVG) were determined. MG was calculated as:

$$
M G=\frac{\sum_{i=1}^{k} n_{i}}{N} \times 100
$$

where,

$n_{i}=$ number of seeds germinated at interval $i$.

$N=$ total number of seeds germinated

The mean coefficient of velocity of germination (MCVG) was obtained as:

$$
M C V G=\frac{\sum_{i=1}^{k} n_{i} t_{i}}{\sum_{i=1}^{k} n_{i}} \times 100
$$

where,

$n_{i}=$ number of seeds germinated at interval $i$.

$t_{i}=$ time interval corresponding to $n_{i}$.

For both experiments, for each germinated seedling, the following biometric parameters were registered: main root length (LR), hypocotyl length (LH), number of lateral root (NLR), length of lateral root (LLR), fresh weight (FW).

\section{Statistical analyses}

The experiments were laid out with a full factorial design with 3 replicates for each treatment. Each experiment was replicated twice.

Statistical analyses were performed in RStudio application of R software (R Core Team, 2014) environment (packages lme4, emmeans, multicomp). The examined biometric traits, after having checked the main assumption of normality and homoscedasticity, were processed using a linear model in a two-ways ANOVA.

MG and MCVG were processed using a generalized linear model with a quasi-binomial distribution using a logit link function.

The significance of differences between treatment means was evaluated by Tukey's test at $\mathrm{P}<0.05$. 


\section{Results and discussion}

The present study explored the mitigation effects of two osmolytes (GB and Pro) on some biometric and germination parameters recorded on $P$. vulgaris seeds grown under two different temperature conditions $\left(20^{\circ} \mathrm{C}\right.$ and $\left.25^{\circ} \mathrm{C}\right)$ and stressed by two $\mathrm{F}$ sources ( $\mathrm{KF}$ and $\mathrm{NaF}$ ).

The results of two-ways ANOVA for both experiments are reported in Table 1. In both cases, the growth and development of $P$. vulgaris seedlings were negatively affected by both F sources, but exogenous addition of GB and Pro unveiled enhancement in germination and biometric parameters (Table 1; Figure 1).

\section{Experiment \#1}

At higher temperature $\left(25^{\circ} \mathrm{C}\right.$, experiment $\left.1, \operatorname{Exp} 1\right)$, the two sources of $\mathrm{F}$ dramatically reduced the germination percentage (MG), from 75\% (F0) to $0 \%$ (KF and $\mathrm{NaF} 200 \mathrm{ppm}$ ) (Figure 1A). The exogenous application of GB significantly increased MG both in control condition and under KF treatment, while Pro enhanced significantly $\mathrm{MG}$ in all the tested conditions.

The mean coefficient of velocity of germination (MCVG) showed the same significance of MG depending on salts and osmolytes, which highlighted the role of Pro addition to fasten the germination process in all the treatments and to mitigate the toxicity effect due to salts. GB addition was able to replicate the same performance already discussed for Pro only under control and KF treatment (Figure 1B). These results were partially in disagreement

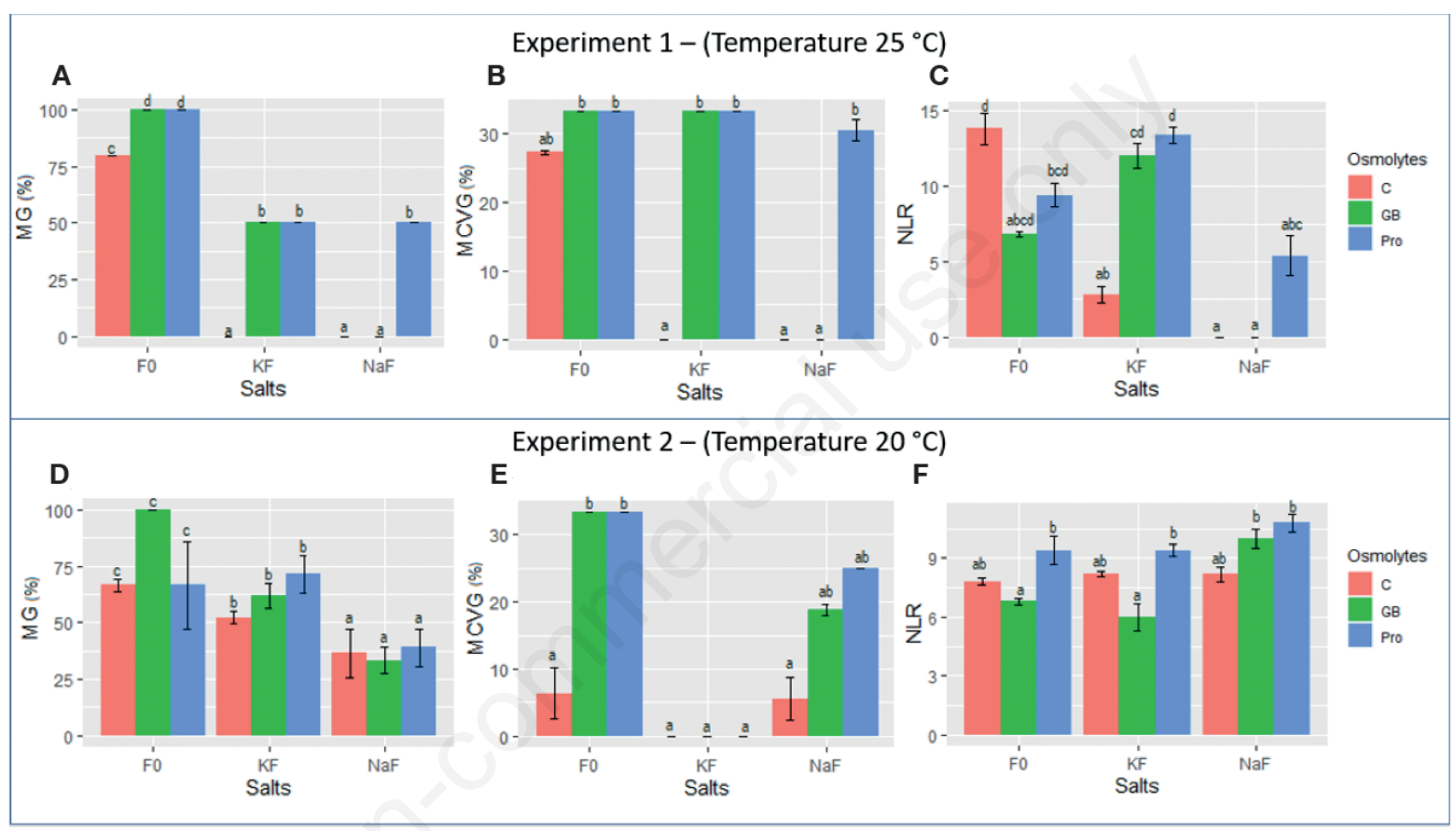

Figure 1. Mean germination percentage (MG), mean coefficient of velocity of germination (MCVG) and number of lateral roots (NLR) under three salt levels: $0, \mathrm{KF}(200 \mathrm{ppm})$ and $\mathrm{NaF}(200 \mathrm{ppm})$ and supplied with three levels of osmolytes: control (C, no osmolytes), glycinbetaine $(\mathrm{GB}: 75 \mu \mathrm{M})$, proline (Pro: $10 \mathrm{mmol})$ tested at $25^{\circ} \mathrm{C}(\mathrm{A}, \mathrm{B}, \mathrm{C})$ and at $20^{\circ} \mathrm{C}(\mathrm{D}, \mathrm{E}$, F). Vertical bars represent standard error. Different combinations of lower case letters indicate significantly differing means $(P<0.05$, Tukey's test $)$.

Table 1. Significance of the effects of salts, osmolytes and their interaction on biometric and germination parameters.

\begin{tabular}{|c|c|c|c|c|c|c|c|}
\hline & LR & LLR & NLR & FW & LH & MG & MCVG \\
\hline \multicolumn{8}{|c|}{ Experiment \#1 } \\
\hline Salts & $* * *$ & $* * *$ & $* * *$ & $* * *$ & $* * *$ & $* * *$ & $* * *$ \\
\hline Osmolytes & & & $* *$ & $* * *$ & & $* * *$ & $* * *$ \\
\hline Salts $\times$ osmolytes & & & $* * *$ & $* * *$ & $* *$ & $* * *$ & $* * *$ \\
\hline \multicolumn{8}{|c|}{ Experiment \#2 } \\
\hline Salts & $* *$ & $* * *$ & & $* * *$ & $* * *$ & $*$ & $* * *$ \\
\hline Osmolytes & $* *$ & $* * *$ & * & $* * *$ & * & & $* * *$ \\
\hline Salts $\times$ osmolytes & & $* * *$ & & $* * *$ & & & \\
\hline
\end{tabular}


with a previous study conducted by Yadu et al. (2017) which confirmed that GB significantly alleviated the inhibition in germination and overall growth responses induced by $\mathrm{F}$ in Cajanus cajan L. The apparent discrepancy could be associate to the high level of $\mathrm{NaF}$ used $(200 \mathrm{ppm})$ in this research compared to $75 \mathrm{ppm}$ reported by the authors and the quantity of exogenous GB applied, beyond the test species which were different.

However, our results regarding the Pro effect are confirmed by several research studies highlighting that exogenous application of Pro to plants increase their stress tolerance, providing osmo-protection and promoting bean growth under $\mathrm{KF}$ and $\mathrm{NaF}$ stressed conditions (Dar et al., 2016).

Beside seed germination, $\mathrm{F}$ also affected the seedling growth (data not shown). Data witnessed that $\mathrm{F}$ drastically reduced root length (LR) and hypocotyl length (LH) by $100 \%$ and $75 \%-64 \%$ under $\mathrm{KF}$ and $\mathrm{NaF}$ treatment compared to the control, respectively. As previously reported, GB and Pro, under abiotic stress condition, increase the rate of cell division and elongation, and improves the plant growth (Luo et al. 2015). This was not confirmed in our study, where seedlings growth was partially inhibited after the addition of GB and Pro under F stress (data not shown). Without salts application, GB and Pro enhanced both LH and LR up to values recorded for the control (data not shown).

In this study, lateral roots were monitored as well. Length and number of lateral roots (LLR; NLR) significantly decreased as response to salts stress (Table 1). In general, the addition of Pro induced a recovery of about $10 \%$ and $50 \%$ of LLR in plant treated with $\mathrm{KF}$ and $\mathrm{NaF}$, respectively. No effect was observed after GB application (data not shown). Furthermore, NLR was significantly affected by $\mathrm{F}$ addition with specific osmolyte response (Table 1; Figure 1C). Without salt, the highest NLR was observed in F0 (13.80) (Figure 1C), while the addition of GB and Pro reduced NLR (6.80 and 9.40 respectively). Under F, a significant reduction of NLR was detected compared to control condition (2.80 and 0 for $\mathrm{KF}$ and NaF, respectively). The addition of osmolytes deeply impacted the NLR with a salt specific response. Under KF treatment, Pro induced a complete recovery of NLR, obtaining a quite same value recorded in F0 (13.40); while GB showed an almost complete restoration of NLR value (12.0). Under NaF treatment, the addition of GB did not have effect on NLR recovery, while Pro addition was able to recover about $39 \%$ of NLR.

\section{Experiment \#2}

When the experiment was performed at lower temperature $\left(20^{\circ} \mathrm{C}\right.$; Experiment 2, Exp2), osmolytes and salts showed different effects on germination and seedlings growth compared to the Exp1. These differences might be associated to the combined effect of higher temperature and salinity for Exp1 and to the only salts effect in Exp2.

Overall, the addition of $\mathrm{F}$ induced a significant reduction of MG (Table 1; Figure 1D) compared to the control. In F0, the addition of GB increased MG from $70 \%$ (F0) to the maximum value of $100 \%$, while Pro kept the same germination value observed in F0. A significant reduction of $\mathrm{MG}$ has been induced after the addition of $\mathrm{KF}$ (approx. 50\%) and $\mathrm{NaF}$ (approx. 30\%). Indeed, the osmolytes addition showed more effectiveness under KF treatment than under $\mathrm{NaF}$. In particular, both osmolytes added to KF completely restored $\mathrm{MG}$ to $\mathrm{F} 0$ value, while under $\mathrm{NaF}$ a teeny improvement was observed.

The effect of GB and Pro was more evident on MCVG. This parameter, without salts, increased six times after osmolytes addition. Differently, it remained stable and equal to zero under KF treatment, while it changed with Pro and GB addition under $\mathrm{NaF}$ treatment, underlying the importance of adding osmolytes in con- dition of high salt stress to fasten germination process (Figure 1E). At lower temperature both salts halved LR (data not shown). Under KF treatment, Pro completely restored LR, even exceeding LR values recorded under F0 treatment, while GB showed a limited effect with almost no difference with the KF treatment (data not shown). Under NaF, the two osmolytes showed a different trend. GB demonstrated a better recovery activity compared to Pro. Indeed, Pro application enhanced LR reaching values closed to F0 condition, while LR obtained with GB application overcame those values.

LH increased significantly with osmolytes addition while it was significantly reduced by salts treatment (Table 1). KF and $\mathrm{NaF}$ reduced $\mathrm{LH}$ by $76 \%$ and $67 \%$, respectively. The addition of both osmolytes induced a partial recovery of LH, highlighting a better performance of Pro compared to GB. About LH, the best recovery was found in $\mathrm{NaF}+$ Pro $(2.82 \mathrm{~cm})$ thus approaching the average value found under control condition (F0: $3.28 \mathrm{~cm}$ ). As reported in Exp1, also in Exp2 length and number of lateral roots (LLR, NLR) significantly decreased as response to salts stress (Table 1). In general, the addition of Pro induced a recovery of about $50 \%$ and $60 \%$ of LLR in plant treated with $\mathrm{KF}$ and NaF, respectively. GB addition provoked halved effect on LLR compared to GB addition for each tested salt (data not shown).

The effect of F was not significant in terms of NLR (Table 1). Conversely, the addition of Pro was more promising than GB for all salt treatments (Figure 1F).

The literature proved that exogenously application of GB and Pro improved growth and other physiological attributes of plants exposed to abiotic stress (Dar et al., 2016).

GB mitigates adverse effects of salinity stress in different plant species. Indeed, Lutts (2000) reported that foliar application of GB significantly improved salt tolerance in rice plants, while Ashraf and Foolad (2007) reported that exogenous application of GB on tomato plants cultivated under salinity stress increase of about $40 \%$ their fruit yield compared with untreated plants. Moreover, under salt stress, GB may also indirectly protect cells from environmental stresses via its function in signal transduction, thanks to its role in $\mathrm{Na}^{+} / \mathrm{K}^{+}$discrimination, which substantially or partially contributes to plant salt tolerance ((Dar et al., 2016). However, a better understanding of GB mechanism of action and the magnitude of its effects on different plant species would be essential to implement its application.

Exogenously applied Pro plays also an important role in enhancing plant stress tolerance. Pro can protect cell membranes from various environmental stresses by enhancing activities of antioxidants. An involvement of Pro in developmental processes, seed germination, flower transition, flower development and other developmental processes have been reported by Dar et al. (2016) but further research is necessary to better identify its role against abiotic stresses.

\section{Conclusions}

The results of this study, for the first time, described the specific role of Pro and GB in improving F stress tolerance in P. vulgaris at early stage of plant development.

Even though limitations exist for extrapolating results to the field scale, such as the study was focused on the very early stage of development of $P$. vulgaris, we tried to accurately quantify the effects of exogenous applications of GB and Pro to bean seeds under $\mathrm{F}$ stress, on germination parameters and seedling biometry in order to draw a clear idea of what happens in the period immediately following germination. 
In this phase, the beneficial effects of external supply of osmoprotectants changed depending on temperature and the severity of salt stress. In this study, Pro was more effective than GB in alleviating the undesirable effects of $\mathrm{F}$ stress on some morphological attributes caused by $\mathrm{NaF}$.

Therefore, for effective application and commercial use of exogenous GB and Pro as biostimulants of crop to reach F stress tolerance, the mechanisms of actions of these compounds, the optimal concentrations depending on the susceptibility of the species and the specific salt stress condition, and the most appropriate plant developmental stage in which performing the application still need to be carefully determined.

\section{References}

Annunziata MG, Ciarmiello L F, Woodrow P, Dell'Aversana E, Carillo P, 2019. Spatial and temporal profile of glycine betaine accumulation in plants under abiotic stresses. Front. Plant Sci. 10:230, 1-13.

Ashraf M, Foolad MR, 2007. Roles of glycine betaine and proline in improving plant abiotic stress resistance. Environ. Exp. Bot. 59:206-16.

Banerjee A, Roychoudhury A, 2019a. Fluorine: a biohazardous agent for plants and phytoremediation strategies for its removal from the environment. Biol. Plant. 63:104-12.

Banerjee A, Roychoudhury A, 2019b. Structural introspection of a putative fluoride transporter in plants. 3. Biotech. 9:103.

Beebe SE, Rao IM, Mukankusi C, Buruchara RA, 2012. Improving resource use efficiency and reducing risk of common bean production in Africa, Latin America, and the Caribbean. In: Hershey, Clair H. (ed.). Eco-Efficiency: From vision to reality. Centro Internacional de Agricultura Tropical (CIAT), Cali, CO. $18 \mathrm{p}$.

Bharti VK, Giri A, Kumar K, 2017. Fluoride sources, toxicity and its amelioration: a review. Ann. Environ. Sci. Toxicol. 2:21-32.

Binagwa PH, Magdalena W, Michael K, Zakayo E, Mbiu J, Msaky J, Mdachi, M, Kasubiri F, Kisamo A, Nestory SM, Rubyogo JC, 2018. Selian Agricultural Research Institute (SARI) Released Seven (7) Improved Common Bean (Phaseolus vulgaris) Varieties; January 2018. Fact Sheet 1.

Chandrakar V, Dubey A, Keshavkant S, 2016. Modulation of antioxidant enzymes by salicylic acid in arsenic exposed Glycine max L. J. Soil Sci. Plant Nutr. 16:662-76.
Dar MI, Naikoo MI, Rehman F, Naushin F, Khan FA, 2016. Proline accumulation in plants: roles in stress tolerance and plant development. In: N. Iqbal, R. Nazar, A.N. Khan (Eds.), Osmolytes and plants acclimation to changing environment: emerging omics technologies. Springer, New Delhi, India. Available from: https://doi.org/10.1007/978-81-322-2616-1_9

Debska K, Bogatek R, Gniazdowska A, 2012. Protein carbonylation and its role in physiological processes in plants. Postepy Biochem. 58:34-43.

Demilìr Y, Kocaçalişkan İ, 2001.Effects of $\mathrm{NaCl}$ and proline on polyphenol oxidase activity in bean seedlings. Biol. Plant. 44:607-9.

Lutts S, 2000. Exogenous glycinebetaine reduces sodium accumulation in salt-stressed rice plants. IRRN 25:9-40.

Mondal D, Gupta S, 2015. Influence of fluoride contaminated irrigation water on biochemical constituents of different crops and vegetables with an implication to human risk through diet. J. Mater. Environ. Sci. 6:3134-2.

Nounjan N, Nghia PT, Theerakulpisut P, 2012. Exogenous proline and trehalose promote recovery of rice seedlings from saltstress and differentially modulate antioxidant enzymes and expression of related genes. J. Plant Physiol. 169:596-604.

Panda D, 2015. Fluoride toxicity stress: physiological and biochemical consequences on plants. Int. J. Bio-res. Env. Agril. Sci.1:70-84.

Rady MM, Taha RS, Mahdi AHA, 2015. Proline enhances growth, productivity and anatomy of two varieties of Lupinus termis L. Grown under salt stress. S. Afr. J. Bot. 102:221-7.

Sofy MR, Elhawat N, Alshaal T, 2020. Glycine betaine counters salinity stress by maintaining high $\mathrm{K}+/ \mathrm{Na}+$ ratio and antioxidant defense via limiting $\mathrm{Na}+$ uptake in common bean (Phaseolus vulgaris L.). Ecotoxicol. Environ. Safety 200:1-12.

Wortmann CS, Kirkby R, Eledu C, Allen DJ, 1998. Atlas of common bean production in Africa. Centro Internacional de Agricultura Tropical, Cali, Colombia. 133 p. Illus. -- (CIAT publication; no. 297).

Yadu B, Chandrakar V, Keshavkant S, 2016. Responses of plants to fluoride: An overview of oxidative stress and defense mechanisms. Fluoride 49:293-302.

Yadu B, Chandrakar V, Meena RK, Keshavkant S, 2017. Glycinebetaine reduces oxidative injury and enhances fluoride stress tolerance via improving antioxidant enzymes, proline and genomic template stability in Cajanus cajan L. S. Afr. J. Bot. 111:68-75. 